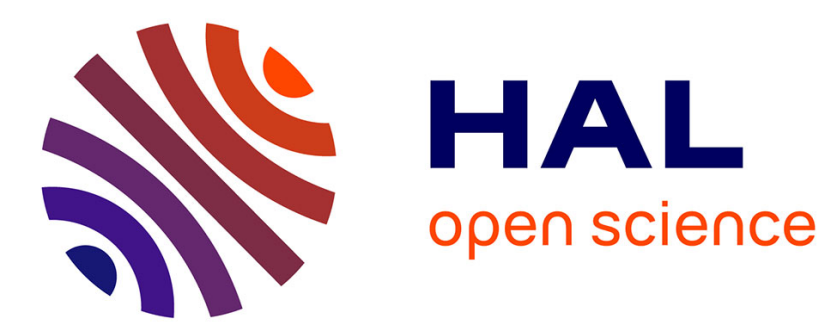

\title{
Density functional theory study of CO-induced segregation in gold-based alloys
}

Adnene Dhouib, Myriam Sansa, Hazar Guesmi

\section{To cite this version:}

Adnene Dhouib, Myriam Sansa, Hazar Guesmi. Density functional theory study of CO-induced segregation in gold-based alloys. Journal of Chemical Physics, 2014, 141 (6), pp.064709. 10.1063/1.4891869 . hal-01081152

\section{HAL Id: hal-01081152 https://hal.science/hal-01081152}

Submitted on 14 Apr 2021

HAL is a multi-disciplinary open access archive for the deposit and dissemination of scientific research documents, whether they are published or not. The documents may come from teaching and research institutions in France or abroad, or from public or private research centers.
L'archive ouverte pluridisciplinaire HAL, est destinée au dépôt et à la diffusion de documents scientifiques de niveau recherche, publiés ou non, émanant des établissements d'enseignement et de recherche français ou étrangers, des laboratoires publics ou privés. 


\title{
Density Functional Theory study of CO-induced segregation in Gold-based alloys
}

Myriam Sansa ${ }^{1}$, Adnene Dhouib ${ }^{2}$ and Hazar Guesmi ${ }^{3 *}$

1 Université de Tunis-El Manar, Laboratoire de spectroscopie Atomique Moléculaire et Applications, Le Belvédère, 1060 Tunis, Tunisie.

2 Université de Carthage, Unité physico-chimie Moléculaire, IPEST- BP51, La Marsa, 2070 Tunis, Tunisie.

3 CNRS-Institut Charles Gerhardt, UMR 5253, équipe MACS, 8 rue de l'Ecole Normale 34296, Montpellier, France.

\begin{abstract}
This paper reports a systematic study of the effect of $\mathrm{CO}$ gas on the chemical composition at the surface of gold-based alloys. Using DFT periodic calculations in presence of adsorbed $\mathrm{CO}$ the segregation behavior of group 9-10-11 transition metals ( $\mathrm{Ag}, \mathrm{Cu}, \mathrm{Pt}, \mathrm{Pd}$, $\mathrm{Ni}, \mathrm{Ir}, \mathrm{Rh}, \mathrm{Co}$ ) substituted in semi-infinite gold surfaces is investigated. Although, $\mathrm{CO}$ is found to be more strongly adsorbed on (100) than on the (111) surface, the segregation of M impurities is found to be more pronounced on the (111) surface. The results reveal two competitive effects: the effect of $\mathrm{M}$ on $\mathrm{CO}$ and the effect of $\mathrm{CO}$ on $\mathrm{M}$. Thus, on one hand, if $\mathrm{M}$ exists on the (100) gold facet, CO would be strongly adsorbed on it. But if $\mathrm{M}$ is initially located in the bulk, it would segregate to the (111) facet instead of the (100) in order to bind to $\mathrm{CO}$.
\end{abstract}

Keywords: Surface segregation, gold-based alloys, transition metals, CO adsorption, reactive gas, DFT. 


\section{Introduction}

Bimetallic alloy surfaces are promising candidates in heterogeneous catalysts design because of the possibility to tune the geometric and surface electronic structures that determine the chemical reactivity [1-2]. Alloying of gold catalysts, for instance, has been found to improve reactivity in a number of reactions including the direct synthesis of hydrogen peroxide from $\mathrm{H}_{2}$ and $\mathrm{O}_{2}$ [3, 4], synthesis of vinyl acetate [5], selective hydrogenation of butadiene [6] and so forth. In the context of CO reforming, many gold based alloy materials AuM (with M=Transition Metal) were introduced [7]. AuNi nanoalloys were reported to be more resistant to poisons than Ni catalysts [8]. Recent experiments on gold nanoparticles with different $\mathrm{Ni}$ contents show an improvement of the $\mathrm{CO}$ oxidation rate [9]. Palladium [10] and platinum [11] also emerge as good candidates for the enhancement of such reaction.

In alloy topic, it is well known that the chemical composition at the surface of alloy systems usually differs from that in the bulk. This is because of the surface segregation which is largely controlled by the surface free energy. However, surface energy alone cannot predict the active surface state of a solid catalyst. The contributions of other parameters such as size and support effects as well as the influence of the adsorbates [1213], play a major role. While the adsorbate-induced segregation of metal alloys under the reaction conditions, and thus the changes in local atomic composition and surface structure have been predicted and demonstrated to occur for a number of gold alloy systems [14-15], no systematic study of AuM alloy systems, addressing the correlation between the surface energy of the constituent metals and the adsorption energy of reactant molecules and their effect on the segregation of the elements, exists. To gain a clear understanding at the molecular-level reactivity of $\mathrm{CO}$ interacting with gold-based alloy catalysts, model systems composed of gold surfaces doped with transition metals were systematically considered. Thus, the energetic and the electronic structures of the effect of $\mathrm{CO}$ interaction are studied in a series of doped $\mathrm{Au}(111)$ and $\mathrm{Au}(100)$ surfaces.

In this paper, the results are organized as follows: in the first part the main characteristics of different considered alloy systems are discussed. Then the segregation behavior under vacuum, of group 9, 10 and 11 metal impurities diluted in gold matrix are investigated through the calculation of segregation energies of $\mathrm{M}$ (isolated atom) on low index $\mathrm{Au}$ (100) and (111) surfaces. Secondly, CO interactions with alloy surfaces and new segregation behaviors in presence of gas molecule are discussed. Finally, AuM surface 
structures in the presence of $\mathrm{CO}$ are described based on electronic and energetic analysis and discussed in detail to amend a general behavior of bimetallic alloys under $\mathrm{CO}$ gas.

\section{Computational details}

All calculations were performed using the ab-initio plane-wave pseudo-potential approach as implemented in VASP [16-17]. The generalized gradient approximation functional of the exchange-correlation energy was calculated within the Perdew, Burke, and Ernzerhof formulation of the generalized-gradient approximation (GGA-PBE) [18]. The valence electrons were treated explicitly, and their interactions with the ionic cores were described by the projector augmented-wave method (PAW) [19]. The selected description of the oxygen atomic core allows a good convergence on the energy for a cutoff of $450 \mathrm{eV}$. The convergence criterion for the electronic self-consistent cycle was

fixed to $10^{-6} \mathrm{eV}$ per supercell. Geometry optimizations were performed within a conjugate-gradient algorithm until the convergence criterion on forces $\left(10^{-2} \mathrm{eV} \cdot \AA^{-1}\right)$ was reached. A dipolar correction along the perpendicular to the slab was applied in order to remove the effect of electrostatic interaction between the slab and its periodic images along the $\mathrm{z}$ axis. The $\operatorname{AuM}(111)$ and $\operatorname{AuM}(100)$ systems with $\mathrm{M}=(\mathrm{Ag}, \mathrm{Cu}, \mathrm{Pt}, \mathrm{Pd}, \mathrm{Ni}, \mathrm{Ir}$, $\mathrm{Rh}$ and $\mathrm{Co}$ ) were modelled with periodic approach by considering slabs of six atomic layers representing $3 \times 3$ supercell, separated by $15 \AA$ of vacuum space. The upper four layers of the surface were allowed to relax, while the remaining layers were fixed at the bulk geometry with a calculated equilibrium lattice constant of $4.17 \AA$ compared to the experimental value of $4.08 \AA$ A20]. The Brillouin zone integrations were performed on a

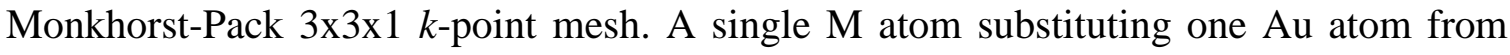
different layer position of the surface, and a single $\mathrm{CO}$ molecule was adsorbed per unit cell; this yields to coverage of 0.11 monolayer (ML) of CO. The adsorption energy of carbon monoxide on the AuM surfaces was calculated as described by equation 1:

$\Delta \mathrm{E}_{\mathrm{ads}}(0 \mathrm{~K})=\mathrm{E}_{\mathrm{CO} / \text { surf }}-\left(\mathrm{E}_{\text {surf }}+\mathrm{E}_{\mathrm{COfree}}\right)$

where $\mathrm{E}_{\text {surf }}$ represents the energy of bare surface alloy, $\mathrm{E}_{\text {Cofree }}$ is the energy of CO gas, and $\mathrm{E}_{\mathrm{CO} / \text { surf }}$ is the energy of the adsorbed system.

For the calculation of segregation energies of metallic impurities $M$ in the presence and absence of $\mathrm{CO}$, metallic atom $\mathrm{M}$ was substituted in different layers of the $\mathrm{Au}(111)$ and 
$\mathrm{Au}(100)$ surfaces as in references [21-23]. The segregation energy $\left(E_{\text {seg. }}\right)$ of $\mathrm{M}$ in gold matrix was defined by equation 2 .

$\Delta E_{\text {seg. }}=\left[E_{M A u(M x \text {-layer })}-E_{M A u(M 4 \text { th-layer })}\right]$

where $E_{\mathrm{AuM}(\mathrm{M} \text { x-layer) }}$ represents the total energy of the AuM alloy system with $\mathrm{M}$ atom located in the upper $\mathrm{x}$ gold layers $(\mathrm{x}=1,2$ or 3$)$ as illustrated by Figure 1 , and $E_{A u M(M} 4 t h$ layer) represents the total energy of the AuM alloy system with the $\mathrm{M}$ atom located in the $4^{\text {th }}$ gold layer, which corresponds to the presence of M impurity in the "bulk" gold. In the presence of adsorbed $\mathrm{CO}$ molecule, the segregation energies were calculated by considering the energetically most stable configuration regarding the position of $\mathrm{M}$ in gold slabs. More positive (negative) is the value of $E_{\text {seg. }}$ more the $\mathrm{M}$ impurity prefers to be in the bulk (surface).

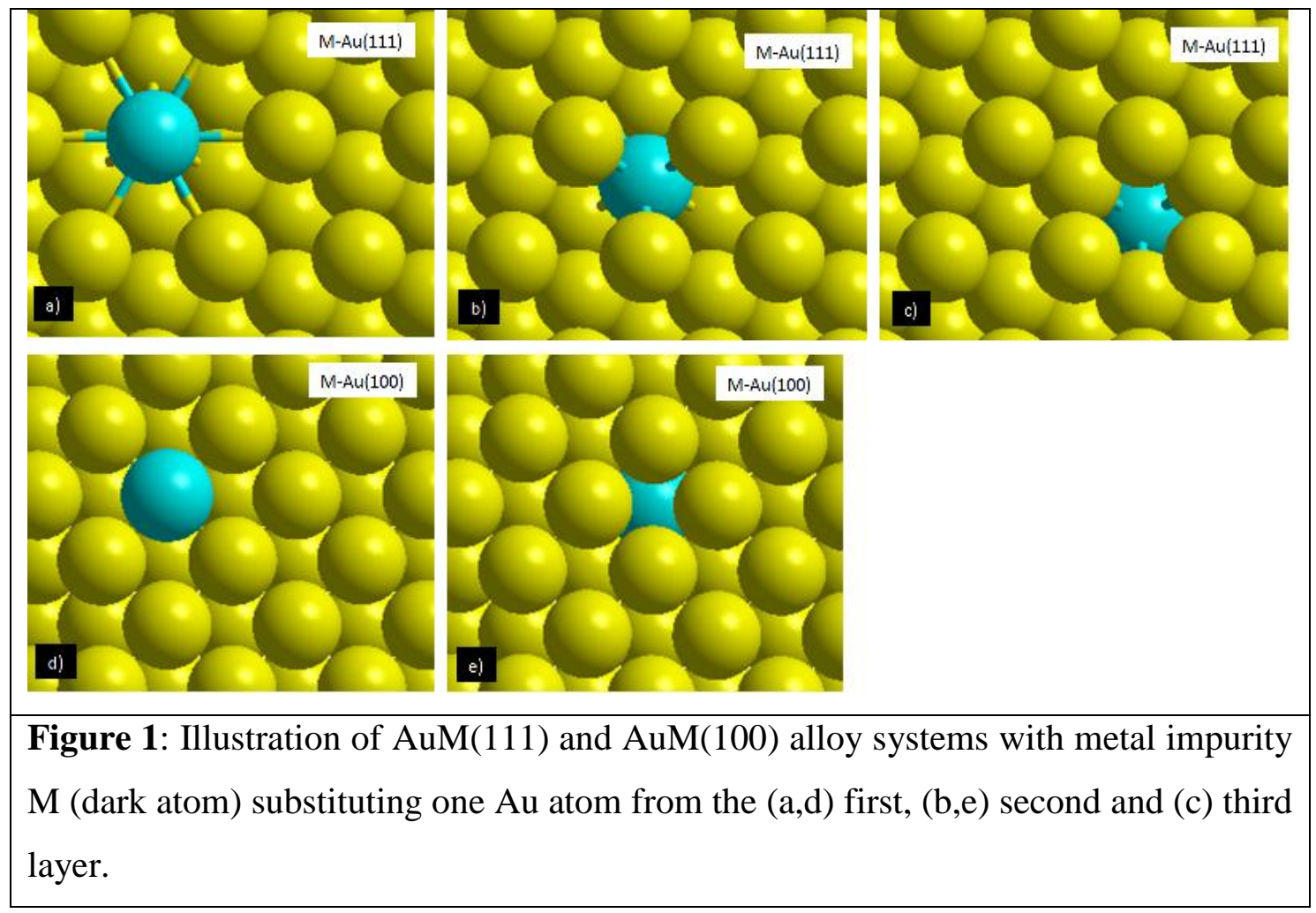

\section{Results and discussion}

\subsection{Surface segregation under vacuum}

The chemical composition at the surface of a bimetallic system often differs from that in the bulk. This phenomenon, called surface segregation, is largely controlled by the surface free energy. For discussion, the experimental surface free energies [24] as well as 
atomic radius [20] (values in brackets) of all considered $3 \mathrm{~d}, 4 \mathrm{~d}$ and $5 \mathrm{~d}$ transition metals are displayed in Figure 2.

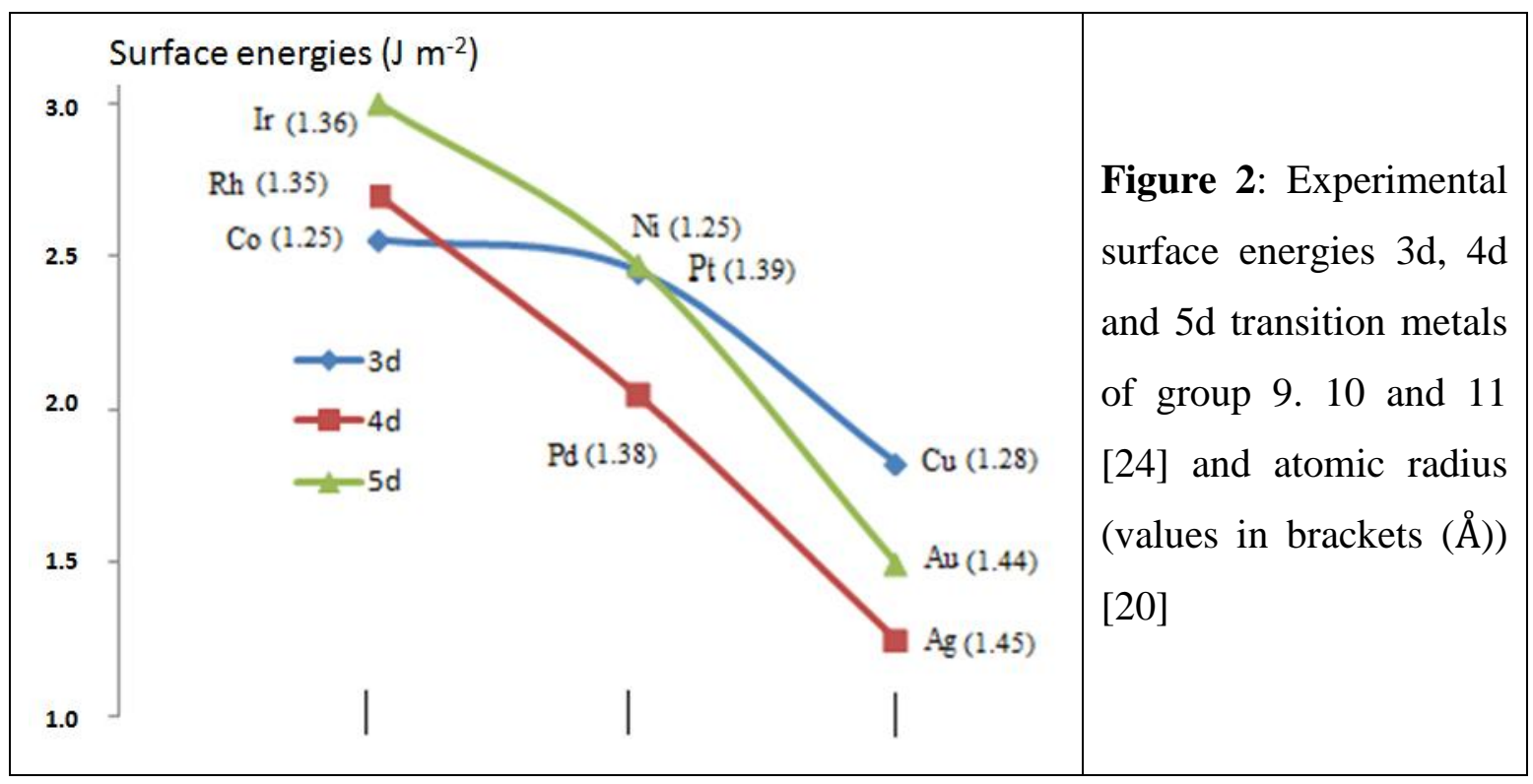

Except for silver, all transition metals (M) in groups 9, 10 and 11 of the periodic table have higher surface energies and lower atomic radius than those of gold. This predicts a surface segregation of gold atoms in AuM alloy systems. Figures 3A and 3B report the evolution of DFT segregation energies $\mathrm{E}_{\text {seg. }}$ (calculated from Eq. (2)) of M impurities in $\mathrm{Au}(111)$ and $\mathrm{Au}(100)$ matrixes, respectively.

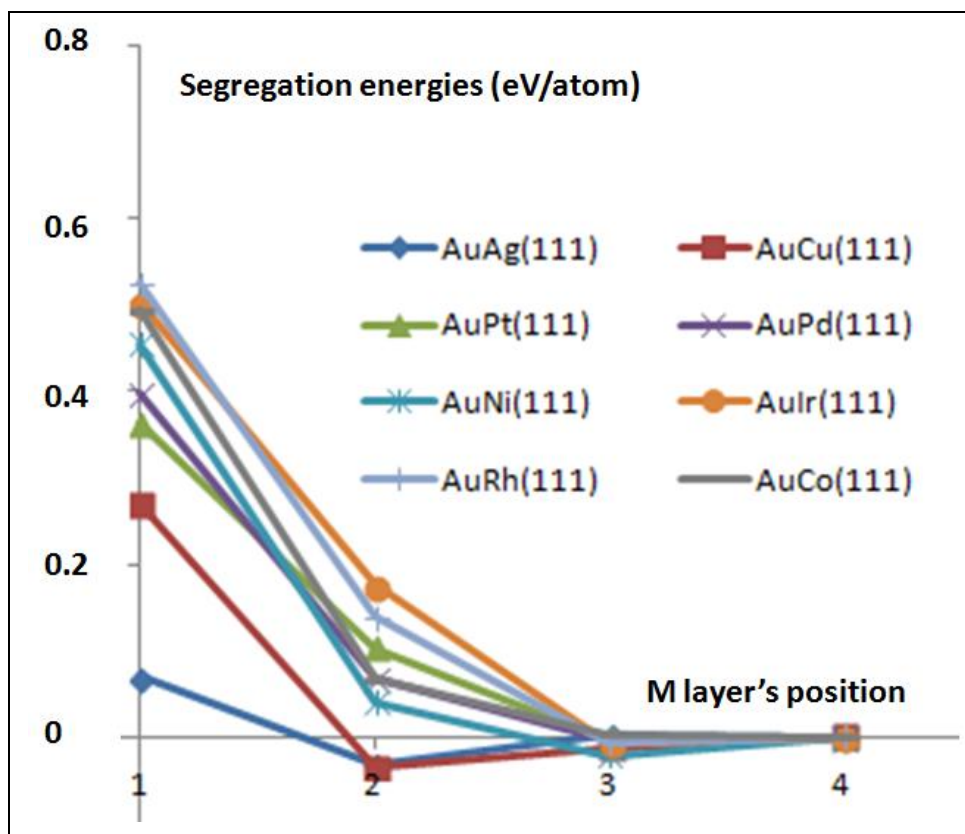

A) 


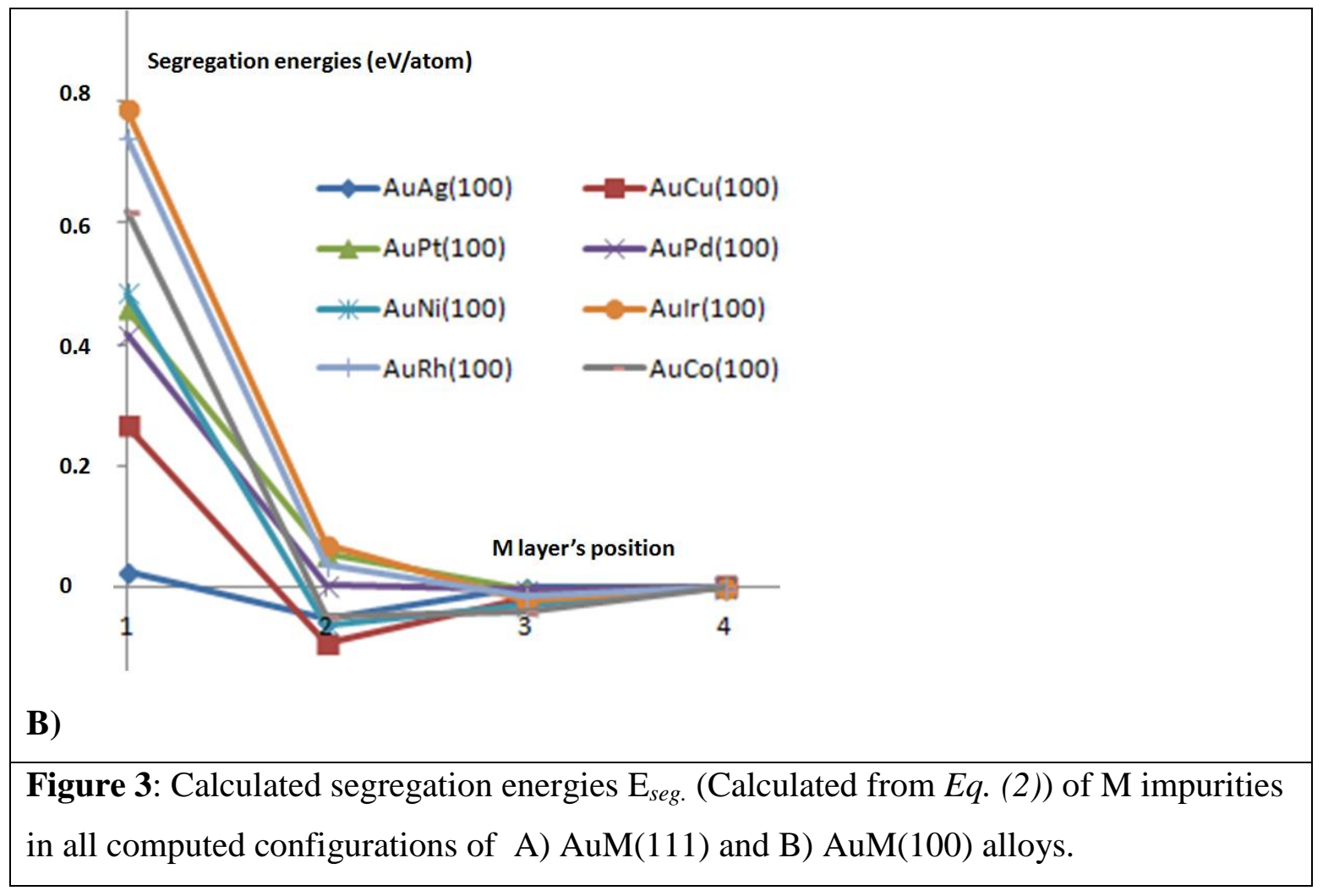

Table 1: Under vacuum; DFT segregation energies $\Delta \mathrm{E}_{\text {seg. }}$. (calculated from $E q$. (2)) of $\mathrm{M}$ impurities in $\mathrm{Au}(111)$ and $\mathrm{Au}(100)$ matrixes and relative segregation anisotropy values.

\begin{tabular}{|c|c|c|c|}
\hline \multirow{2}{*}{ AuM } & \multicolumn{2}{|c|}{$\Delta \mathrm{E}_{\text {seg }}(\mathrm{eV})$} & Segregation anisotropy $(\mathrm{eV})$ \\
\cline { 2 - 4 } & $(111)$ & $(100)$ & $\mathrm{E}_{\mathrm{seg}(111)}-\mathrm{E}_{\mathrm{seg}(100)}$ \\
\hline $\mathrm{Ag}$ & 0.069 & 0.023 & 0.046 \\
\hline $\mathrm{Cu}$ & 0.271 & 0.265 & 0.006 \\
\hline $\mathrm{Pt}$ & 0.364 & 0.458 & -0.094 \\
\hline $\mathrm{Pd}$ & 0.397 & 0.416 & -0.019 \\
\hline $\mathrm{Ni}$ & 0.454 & 0.484 & -0.030 \\
\hline $\mathrm{Ir}$ & 0.503 & 0.788 & -0.285 \\
\hline $\mathrm{Rh}$ & 0.525 & 0.741 & -0.216 \\
\hline $\mathrm{Co}$ & 0.494 & 0.620 & -0.126 \\
& & & \\
\hline
\end{tabular}

As it can be seen in both figures, the segregation behaviors of $M$ impurities in gold almost follow the order of surface energy increasing, particularly on (100) bimetallic surface. Thus, the positive energetic values of $E_{\text {seg }}$ on the first surface layer 
indicate a systematic segregation of gold and the preference of all metal impurities $\mathrm{M}$ to be on the bulk.

Interestingly, according to the chemical nature of $\mathrm{M}$ impurity, its low stability on the surface could depend or not on the orientation. This could be illustrated by the segregation anisotropy values reported in Table 1. The segregation anisotropy were calculated as the difference between the segregation energy of $\mathrm{M}$ impurity (located on the first layer) of (111) and of (100) surfaces. Large negative values of segregation anisotropy were found for $\mathrm{Co}, \mathrm{Rh}$ and $\mathrm{Ir}$ which indicate a strong preference of these impurities to segregate toward the more compact (111) surface. This behavior could be related to two effects which are the surface bond breaking (3 for (111) and 4 for (100) surface) and the strong cohesive energy of the corresponding $\mathrm{M}$ impurity $\left(4.44 \mathrm{eV}\right.$ atom $^{-1}$

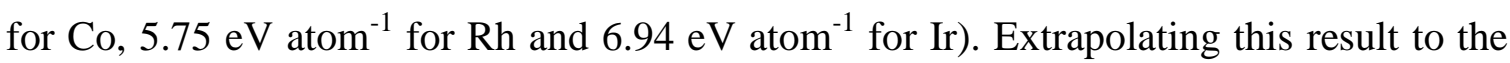
AuM nanoparticles (generally formed by (111) and (100) facets), one could predict to find more $\mathrm{M}$ impurities of group 9 on the (111) facets than on the (100). In contrast, for $\mathrm{AuCu}, \mathrm{AuPd}$ and $\mathrm{AuNi}$ alloy systems no significant effect of surface orientation is found. For AuAg alloy, the calculated segregation energies of Ag impurity on the first surface layer are so small that we cannot directly predict favorable segregation of elements. The atomic radius in elemental $\mathrm{Ag}$ and $\mathrm{Au}$ are very similar (1.45 and $1.44 \AA$, respectively), so there is a negligible strain-induced driving force to induce segregation. The electronic structures and chemical properties are also similar, resulting in fairly weak interactions between the gold and silver atoms. These properties are consistent with the phase diagram for silver-gold alloys, which form a continuous series of solid solutions over the entire bulk concentration range. However, many experimental and theoretical studies, for instance, using Ion Scattering technique on clean polycrystalline AuAg surfaces [25-26] or molecular dynamics [27-28] demonstrated unambiguously that silver segregates to these surfaces.

Analyzing the behavior of metal impurities located on the second layer gold surfaces (Figures $3 \mathrm{~A}$ and 3B), it appears that on (100) surface, $\mathrm{Cu}$ impurity strongly prefers to be in the sub-surface layer than in the bulk $\left(E_{\text {seg.(100) }}=-0.094 \mathrm{eV}\right)$. This result corroborates well with experimental founding where earlier Low Electron Energy Diffraction observations [29] on the (100) surface of $\mathrm{Au}_{3} \mathrm{Cu}$ have shown a strong enrichment in $\mathrm{Cu}$ in the second layer with a nearly pure $\mathrm{Au}$ termination. Let us add that the calculated segregation energies of $\mathrm{M}$ impurities located on the $3^{\text {rd }}$ layer of gold slabs are very close to zero, which indicates a bulk like behavior at this position. 


\subsection{CO-induced segregation:}

\subsubsection{CO adsorption}

Different initial configurations with positions close to and far from the metal impurity were considered in the study of the adsorption of $\mathrm{CO}$ molecule on bimetallic surfaces. The numerical results for the most favorable $\mathrm{CO}$ adsorption configuration on each surface alloy are depicted in Table 2. As it can be seen for all AuM surfaces, where the transition metal impurities $M$ are substituted in the first layer of $A u(111)$ and $\mathrm{Au}(100)$, the $\mathrm{CO}$ adsorption is more favorable when $\mathrm{CO}$ interacts with the metal impurity $\mathrm{M}$, with the exception of the adsorption of $\mathrm{CO}$ on $\mathrm{AuAg}(111)$ surface, in which $\mathrm{CO}$ interacts preferentially with gold atom adjacent to the silver impurity. In all other systems the most favorable adsorption sites are the top sites on which the calculated carbonsurface bond lengths vary from $2.03 \AA$ (on pure (111) gold) to $1.75 \AA$ (on AuNi(100)). The interactions of $\mathrm{CO}$ with coinage metal atoms $\mathrm{Au}, \mathrm{Ag}$ and $\mathrm{Cu}$ are predicted to be the smallest (see table 2). In contrast, the presence of highly cohesive metal impurities such as $\mathrm{Ni}, \mathrm{Pt}, \mathrm{Rh}$ or Ir has a strong effect in the stabilization of the $\mathrm{CO}$ adsorption on gold surfaces. Indeed, the $\mathrm{CO}$ adsorption energy varies from moderate values calculated for the pure gold surfaces, i.e., $-0.33 \mathrm{eV}$ on $\mathrm{Au}(111)$ and $-0.53 \mathrm{eV}$ on $\mathrm{Au}(100)$, or $-0.73 \mathrm{eV}$ on $\mathrm{AuCu}(111)$ and $-0.86 \mathrm{eV}$ on $\mathrm{AuCu}(100)$, to a higher adsorption energy value of -2.57 $\mathrm{eV}$ and $-2.67 \mathrm{eV}$ calculated for $\mathrm{CO}$ interaction with $\operatorname{AuIr}(111)$ and $\mathrm{AuIr}(100)$, respectively. For AuAg alloy system, $\mathrm{CO}$ prefers to adsorb on top of gold atom adjacent to the silver impurity (instead of top-Ag site) with an adsorption energy $(-0.47 \mathrm{eV})$ similar to the one calculated on pure $\mathrm{Au}(100)$.

The calculated adsorption energies of $\mathrm{CO}$ on Top of $\mathrm{M}$ impurities suggest a local character for the $\mathrm{CO}$-surface interaction. Indeed, the calculated adsorption energies for $\mathrm{CO}$ on pure metal surfaces $\mathrm{M}$ are very similar to the calculated adsorption energies on the diluted $\mathrm{M}$ impurities in gold surfaces. For instance, the adsorption of $\mathrm{CO}$ on pure $\mathrm{Rh}$ (111) and (100) surfaces are calculated to be of $-2.01 \mathrm{eV}$ (hcp site) and $-2.07 \mathrm{eV}$ (4fh site), respectively. These values are similar to the calculated energies for $\mathrm{CO}$ on top of $\mathrm{Rh}$ impurity in $\mathrm{Au}(111)$, Eads $=-2.05 \mathrm{eV}$ and in $\mathrm{Au}(100)$, Eads $=-2.14 \mathrm{eV}$. In addition, the adsorption energies calculated for $\mathrm{CO}$ adsorbed on gold atoms in the vicinity of $\mathrm{M}$ impurities are similar to those calculated on pure gold surface. Meanwhile, upon the incorporation of $\mathrm{M}$ in gold sub-layers, i.e. when $\mathrm{M}$ impurities are located on the second, 
third or fourth layer of the slab, the CO behaves similarly than on pure gold surface. For instance, adsorption energies of CO on top gold atom with Ir impurity located in the second, third or fourth layer of gold (111) matrix are calculated to be of $-0.37 \mathrm{eV},-0.34$ $\mathrm{eV}$ and $-0.35 \mathrm{eV}$, respectively. These values are very similar to the adsorption values of $\mathrm{CO}$ on pure gold $(-0.33 \mathrm{eV})$.

Table 2: DFT calculated adsorption energies $\Delta \mathrm{E}_{\text {ads }}$ (calculated from equation $E q .(1)$ ) and optimized geometry distances of CO adsorbed on pure gold and AuM (111) and (100) surfaces.

\begin{tabular}{|c|c|c|c|c|}
\hline Surface & Adsorption site & $\Delta \mathrm{E}_{\mathrm{ads}}$ & $\mathrm{d}_{\mathrm{C} \text {-surf }} *$ & $\mathrm{~d}_{\mathrm{C}-\mathrm{O}} * *$ \\
\hline $\mathrm{Au}(111)$ & Top & -0.33 & $2.03(\mathrm{Au})$ & 1.15 \\
\hline $\mathrm{AuAg}(111)$ & Top-Au & -0.33 & $2.02(\mathrm{Au})$ & 1.15 \\
\hline $\mathrm{AuCu}(111)$ & Top-Cu & -0.73 & $1.87(\mathrm{Cu})$ & 1.15 \\
\hline $\operatorname{AuPt}(111)$ & Top-Pt & -1.64 & $1.86(\mathrm{Pt})$ & 1.16 \\
\hline $\operatorname{AuPd}(111)$ & Top-Pd & -1.15 & $1.91(\mathrm{Pd})$ & 1.15 \\
\hline $\mathrm{AuNi}(111)$ & Top-Ni & $\begin{array}{l}-1.60 \\
-1\end{array}$ & $1.76(\mathrm{Ni})$ & 1.16 \\
\hline AuIr(111) & Top-Ir & -2.57 & 1.83 (Ir) & 1.17 \\
\hline$\overline{A u R h}(111)$ & Top-Rh & -2.05 & $1.84(\mathrm{Rh})$ & 1.16 \\
\hline $\mathrm{AuCo}(111)$ & Top-Co & -2.05 & $1.73(\mathrm{Co})$ & 1.17 \\
\hline \multirow{2}{*}{$\mathrm{Au}(100)$} & Top-Au & -0.47 & $2.00(\mathrm{Au})$ & 1.17 \\
\hline & Bridge $\mathrm{Au}-\mathrm{Au}$ & -0.53 & $2.14(\mathrm{Au}) ; 2.14(\mathrm{Au})$ & 1.17 \\
\hline $\operatorname{AuAg}(100)$ & Top-Au & -0.47 & $2.00(\mathrm{Au})$ & 1.15 \\
\hline $\mathrm{AuCu}(100)$ & Top-Cu & -0.86 & $1.85(\mathrm{Cu})$ & 1.15 \\
\hline $\operatorname{AuPt}(100)$ & Top-Pt & -1.72 & $1.85(\mathrm{Pt})$ & 1.16 \\
\hline $\operatorname{AuPd}(100)$ & Top-Pd & -1.21 & $1.90(\mathrm{Pd})$ & 1.16 \\
\hline $\mathrm{AuNi}(100)$ & Top-Ni & -1.68 & $1.75(\mathrm{Ni})$ & 1.16 \\
\hline AuIr(100) & Top-Ir & -2.67 & 1.83 (Ir) & 1.17 \\
\hline $\operatorname{AuRh}(100)$ & Top-Rh & -2.14 & $1.83(\mathrm{Rh})$ & 1.16 \\
\hline $\mathrm{AuCo}(100)$ & Top-Co & -2.14 & $1.73(\mathrm{Co})$ & 1.17 \\
\hline
\end{tabular}

* Distance from the Carbone to the nearest metal atoms on the surface

** C-O bond length 
Table 3: -DFT adsorption energies $\Delta \mathrm{E}_{a d s .}$ (calculated from Eq. (1)) of CO on M impurities in $\mathrm{Au}(111)$ and $\mathrm{Au}(100)$ matrixes and relative adsorption anisotropy values.

\begin{tabular}{|c|c|c|c|}
\hline \multirow{2}{*}{ AuM } & \multicolumn{2}{|c|}{$\Delta \mathrm{E}_{\mathrm{ads}}(\mathrm{eV})$} & Adsorption anisotropy $(\mathrm{eV})$ \\
\cline { 2 - 4 } & $(111)$ & $(100)$ & $\mathrm{E}_{\mathrm{ads}(111)}-\mathrm{E}_{\mathrm{ads}(100)}$ \\
\hline $\mathrm{Ag}$ & -0.33 & -0.47 & 0.14 \\
\hline $\mathrm{Cu}$ & -0.73 & -0.86 & 0.13 \\
\hline $\mathrm{Pt}$ & -1.64 & -1.72 & 0.08 \\
\hline $\mathrm{Pd}$ & -1.15 & -1.21 & 0.06 \\
\hline $\mathrm{Ni}$ & -1.60 & -1.68 & 0.08 \\
\hline $\mathrm{Ir}$ & -2.57 & -2.67 & 0.10 \\
\hline $\mathrm{Rh}$ & -2.05 & -2.14 & 0.09 \\
\hline $\mathrm{Co}$ & -2.05 & -2.14 & 0.09 \\
\hline
\end{tabular}

Concerning the orientation effect, comparison of the adsorption energies on the two considered surface orientations shows small variations of adsorption anisotropy as a function of $\mathrm{M}$ impurities (see Table 3). The $\mathrm{CO}$ interactions are always stronger on the (100) than on the (111) surface. The smaller variation occurs for the AuPd surfaces (+ $0.06 \mathrm{eV})$ and the largest one is found for the AuAg surfaces $(+0.14 \mathrm{eV})$. In addition, considering only adsorption of $\mathrm{CO}$ en Top position, it appears that the strongest anisotropy effect is induced by pure gold since the difference between the $\mathrm{CO}$ adsorption on $\mathrm{Au}(100)(-0.47 \mathrm{eV})$ and on $\mathrm{Au}(111)(-0.33 \mathrm{eV})$ is of $+0.14 \mathrm{eV}$.

\subsubsection{Surface segregation of M elements}

Adsorbate-induced segregation has previously been observed in gold-based alloys, where strong binding of an adsorbate such $\mathrm{CO}$ [23,30], $\mathrm{NO}$ [31-32], $\mathrm{O}$ and $\mathrm{O}_{2}$ [21$22]$ to the metal with the highest cohesive energy causes segregation of that metal to the surface the opposite of what is observed in vacuum. In a recent work, we have reported oxygen-induced segregation of 10 group transition metal impurities $\mathrm{M}(\mathrm{M}=\mathrm{Pt}, \mathrm{Pd}$, and Ni) alloyed with gold. Platinum and Nickel which, as shown before, prefer to be in the gold bulk matrix under vacuum, show a completely reversed segregation in presence of small amount of oxygen [22]. The Pd, which segregation energy was shown to be atomic 
oxygen coverage dependant [21], with more than 1/3 ML being necessary to induce its segregation, shows high stability on the gold surface in presence of only one adsorbed oxygen molecule. In the present work, CO-induced segregations of group 9-10-11 transition metals $(\mathrm{Cu}, \mathrm{Ni}, \mathrm{Pd}, \mathrm{Pt}, \mathrm{Rh}$, and $\mathrm{Co})$, substituted in gold (111) and (100) surfaces are confirmed. These results are illustrated by the negative curves, reported in Figure 4, representing segregation behavior of metal impurities located on the different surface layer of gold. The negative segregation energies indicate the high stability of $\mathrm{M}$ $(\mathrm{Cu}, \mathrm{Pt}, \mathrm{Pd}, \mathrm{Ni}, \mathrm{Ir}, \mathrm{Rh}, \mathrm{Co})$ on the alloy first layer surfaces. Positive but very close to zero energies are predicted for silver located on gold (111) and (100) surfaces.

Table 4: In presence of CO; DFT segregation energies $\mathrm{E}_{\text {seg. }}$ (calculated from Eq. (2)) of $\mathrm{M}$ impurities in $\mathrm{Au}(111)$ and $\mathrm{Au}(100)$ matrixes and relative segregation anisotropy values.

\begin{tabular}{|c|c|c|c|}
\hline \multirow{2}{*}{ CO-AuM } & \multicolumn{2}{|c|}{$\mathrm{E}_{\text {seg }}(\mathrm{eV})$} & $\begin{array}{c}\text { Segregation anisotropy } \\
(\mathrm{eV})\end{array}$ \\
\cline { 2 - 4 } & $(111)$ & $(100)$ & $\mathrm{E}_{\mathrm{seg}(111)}-\mathrm{E}_{\mathrm{seg}(100)}$ \\
\hline $\mathrm{Ag}$ & 0.177 & 0.010 & 0.167 \\
\hline $\mathrm{Cu}$ & -0.128 & -0.136 & 0.008 \\
\hline $\mathrm{Pt}$ & -0.933 & -0.807 & -0.126 \\
\hline $\mathrm{Pd}$ & -0.419 & -0.244 & -0.175 \\
\hline $\mathrm{Ni}$ & -0.796 & -0.738 & -0.058 \\
\hline $\mathrm{Ir}$ & -1.716 & -1.407 & -0.309 \\
\hline $\mathrm{Rh}$ & -1.178 & -0.930 & -0.248 \\
\hline $\mathrm{Co}$ & -1.213 & -1.045 & -0.168 \\
\hline
\end{tabular}




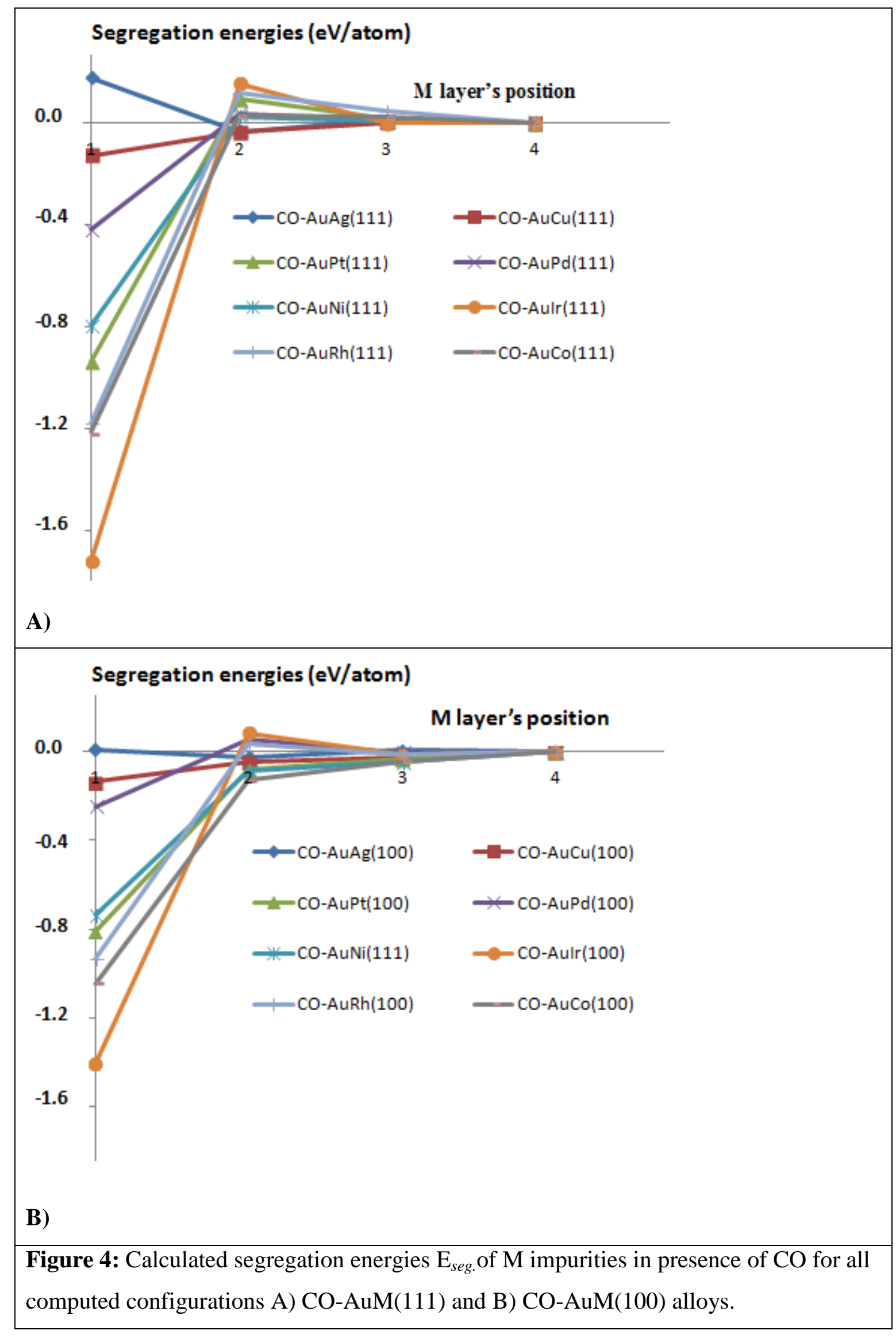


The calculated segregation energies $\left(\mathrm{E}_{\mathrm{seg}}\right)$, in presence of $\mathrm{CO}$ adsorbed on (100) and (111) gold surface layer, see Table 4, show strong segregation anisotropy with energy variation goes from $-0.309 \mathrm{eV}$ for Ir to +0.167 for silver. Except for Ag, the (111) surface remains the preferred orientation for $\mathrm{M}$ segregation interacting with $\mathrm{CO}$. No segregation anisotropy was found for copper.

Interestingly, the stronger adsorption energies of $M$ impurities on (100) alloy surfaces compared to the (111) do not induce a better segregation toward the (100) facet. Indeed, as the adsorption anisotropy is mostly generated by gold and slightly depends on the chemical nature of $\mathrm{M}$, the segregation anisotropy has the same tendency in presence or in absence of $\mathrm{CO}$. To put it simply, except for $\mathrm{Ag}$ and $\mathrm{Cu}$, it is more unfavorable (or less favorable), under vacuum conditions, to put $M$ in the (100) surface then on the (111). This is due to classic reasons of broken bonds (see section 3.1). The adsorption of reactive gas induces the addition of a negative energy which depends more weakly on the orientation and it thus remains always less favorable (more unfavorable) to put $\mathrm{M}$ in the surface (100) then on (111) under $\mathrm{CO}$. For $\mathrm{Ag}$ and $\mathrm{Cu}$, the reasoning remains the same by inverting the signs.

However, deeper analyses of permutation, segregation and adsorption effects are needed to go beyond our simple interpretation on flat surfaces. Indeed, previous DFT energetic and electronic analysis on small AuPd nanoparticles (where only edges and (111) facets exist), show that, under conditions where migration and restructuring can occur, $\mathrm{Pd}$ would migrate towards the edge positions and strongly bind to $\mathrm{CO}[23,33]$.

\subsubsection{Electronic structure analysis}

The density of states (DOS) is an important quantity for understanding the bonding in a compound. According to the d-band model developed by Hammer and Nørskov [34-35], the position of the $d$-band center relative to the Fermi level is the main parameter controlling adsorption. In order to rationalize the trends in $\mathrm{CO}$ adsorption on considered alloy systems, all $\mathrm{M} d$-bands recorded in clean and CO adsorbed $\operatorname{AuM}(111)$ and $\mathrm{MAu}(100)$ surfaces are presented in Figure 5. 


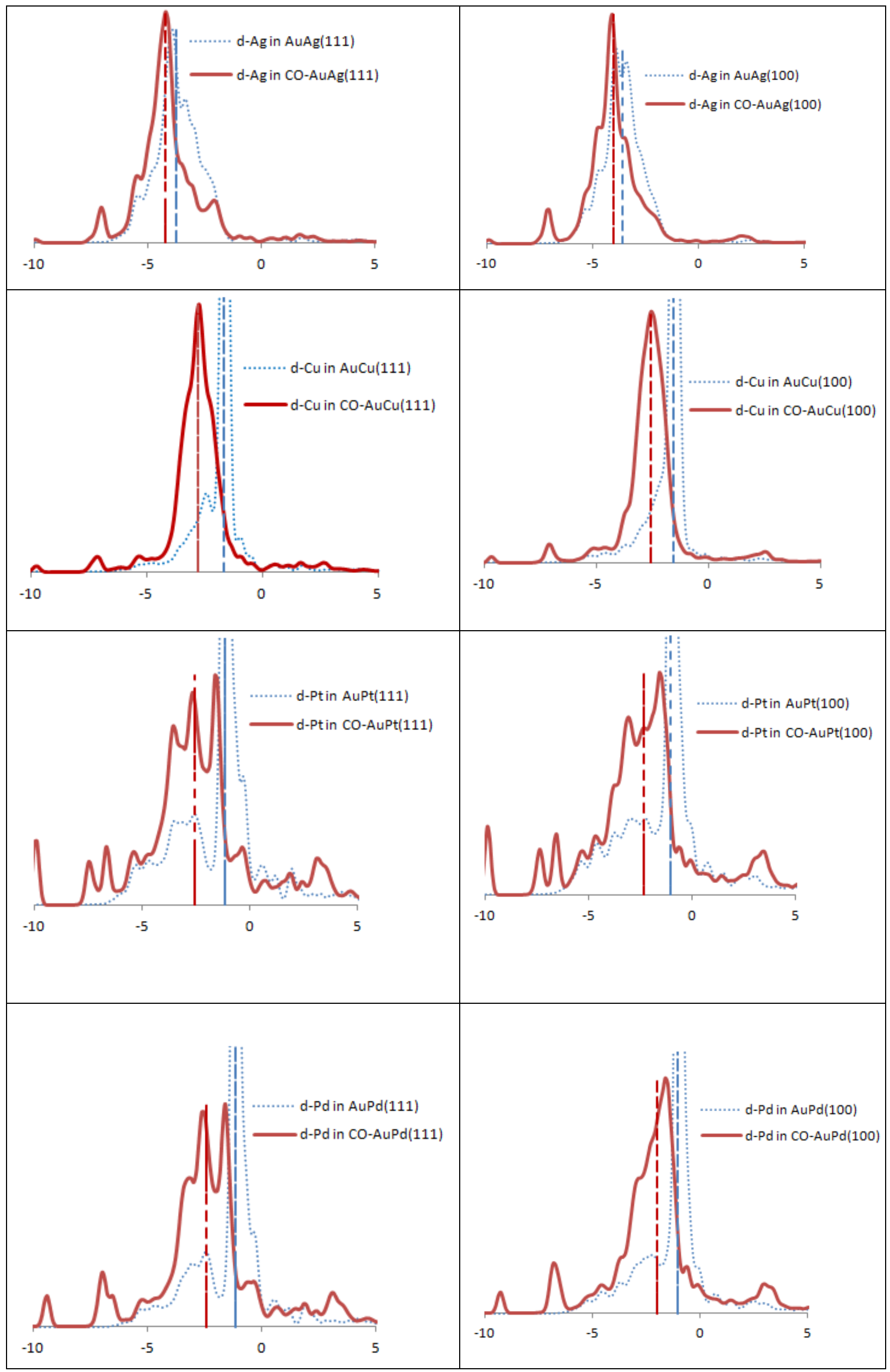




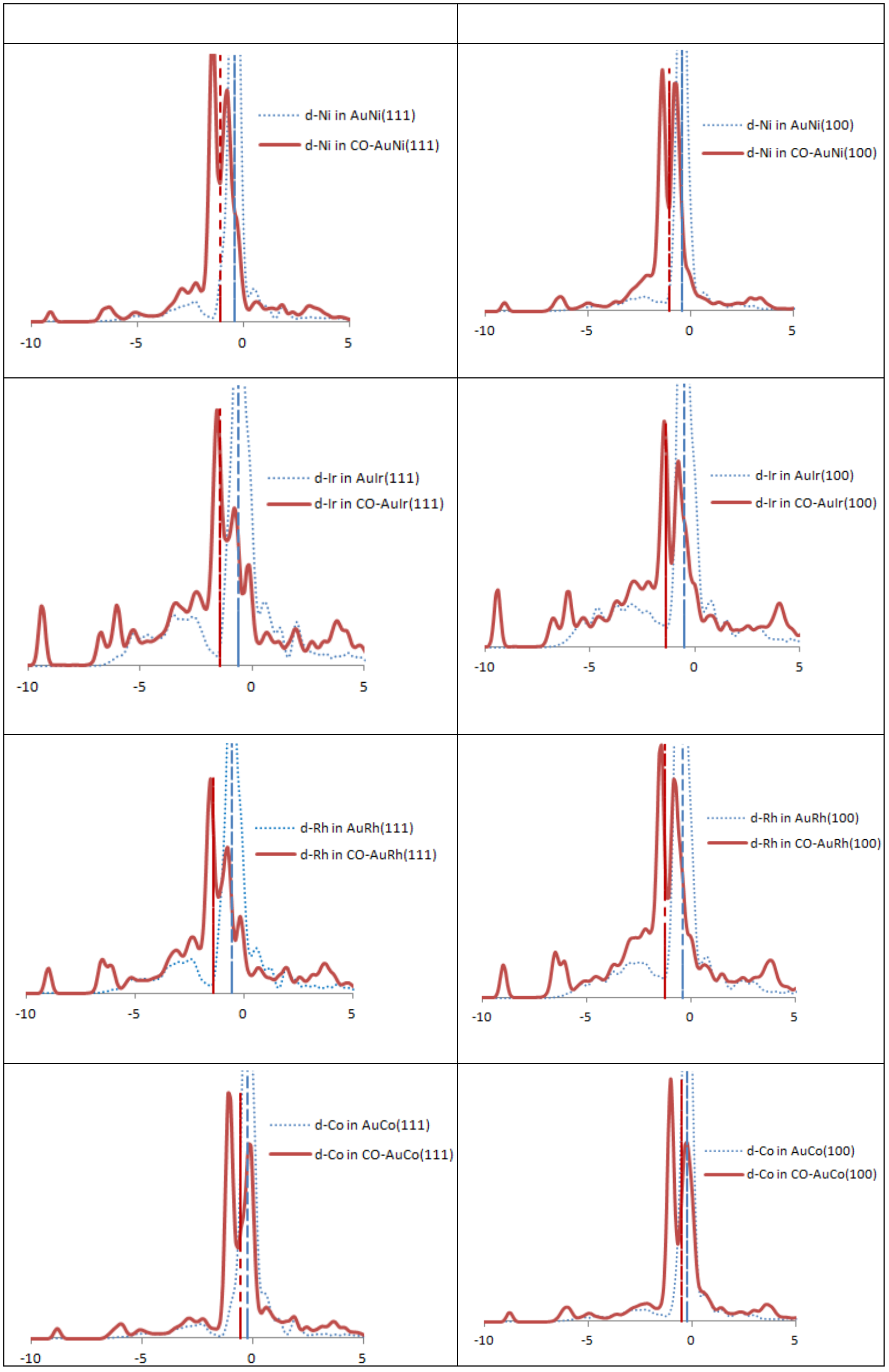


Figure 5: d-band DOSs (states/eV) in clean (dashed bleu lines) and CO-adsorbed (bold red lines) AuM alloy surfaces. Dashed vertical lines correspond to the d-band centers relative to the Fermi energy $\left(\mathrm{E}-\mathrm{E}_{\mathrm{Fermi}}(\mathrm{eV})\right)$.

Under vacuum (clean surfaces), when an $\mathrm{M}$ impurity is diluted in the gold surface layer, its $d$-band is characterized by a narrow peak which lies below the Fermi level. The position of the mean peak toward the Fermi level depends on the density of available $d$ states. Thus, for coinage $\mathrm{M}(\mathrm{Ag}$ and $\mathrm{Cu})$ which are nearly filled $1 \mathrm{~B}$ metals, the position of d-band centers are shifted large away from the Fermi level. This shift is reduced for M metals of group $10(\mathrm{Pt}, \mathrm{Pd}$ and $\mathrm{Ni}$ ) and become very small for ( $\mathrm{Ir}, \mathrm{Rh}$ and $\mathrm{Co})$. After adsorption and due to the overlap between the electronic orbitals of $\mathrm{CO}$ and those of the surface atoms, the width of the d-bands on $\mathrm{M}$ are found to increase. In addition, compared to the clean surfaces, the positions of the d-band centers are systematically up shifted which should indicate an electron donation to the $\mathrm{CO}$ band by an M-atop site surrounded by Au atoms in the bimetallic alloy surfaces. In Figure 6 the upshift in d-band centers of $\mathrm{M}$ atoms, recorded upon CO adsorption, are analyzed for both (111) and (100) surface orientations. The diagram shows a pronounced effect of surface orientation on the AuPd system in which the upshift in $d$-band center on (111) surface is higher by more than $30 \%$ compared to (100) surface. This observed electronic process would predict a different behavior for Pd-CO interactions occurring on the (111) or the (100) facets. A slight effect of the surface orientation is found for $\mathrm{Ni}, \mathrm{Cu}$ and $\mathrm{Pt}$ impurities and no effect is recorded for $\mathrm{Co}, \mathrm{Rh}$ and Ir metal group.

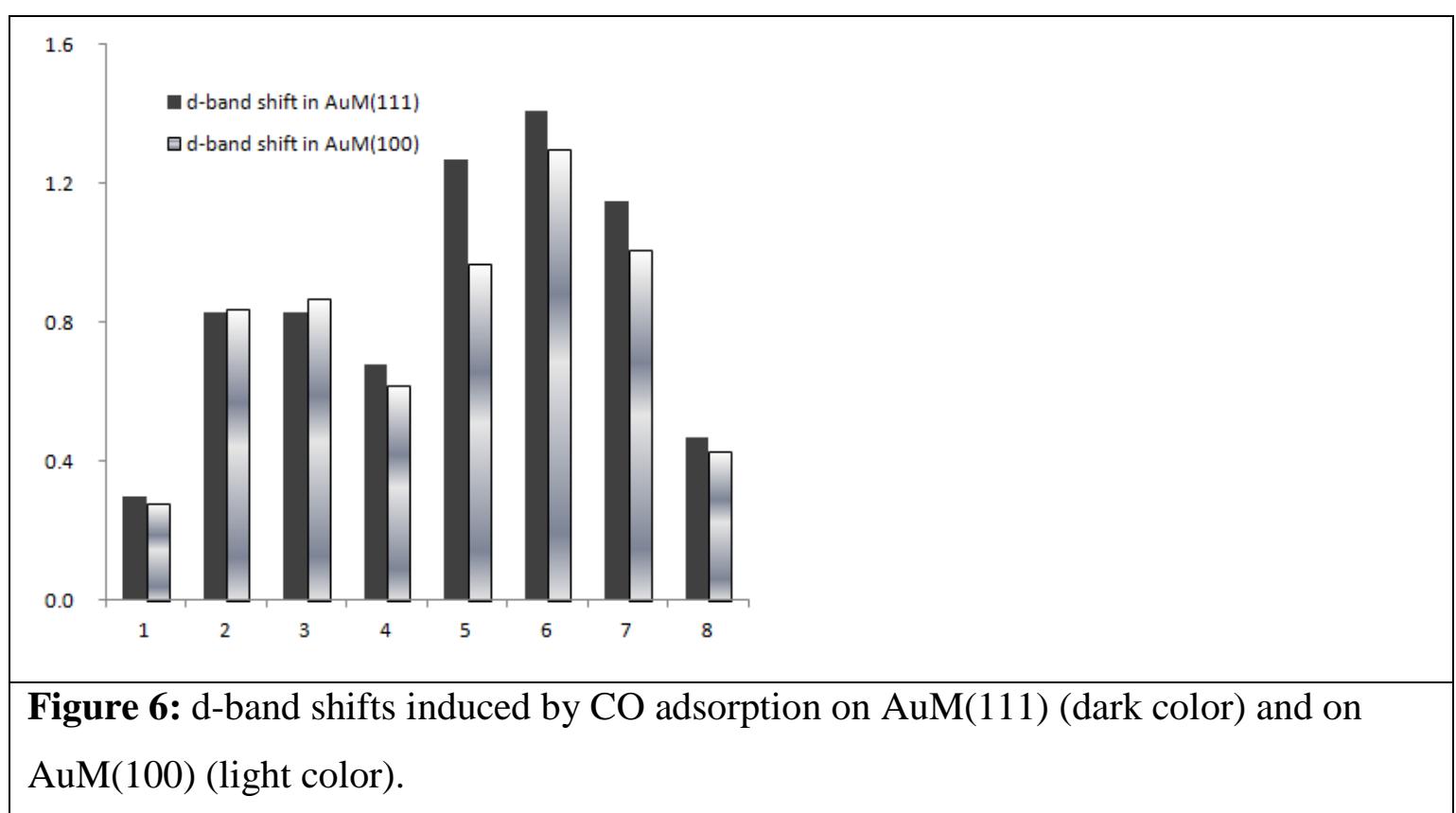




\section{Conclusion}

First-principles total energy calculations and electronic structure analysis were carried out to investigate the effect of $\mathrm{CO}$ on the structure of gold-based alloys. For this purpose, model systems composed of gold surfaces doped with transition metals were considered. The results show a systematic surface segregation of metal impurities in presence of $\mathrm{CO}$ on the surface. To study the effect of surface orientation, energetic and electronic properties are computed and compared on both (111) and (100) surfaces. Obviously, the stability of highly cohesive metal impurities is always stronger in (111) alloy systems; in the bulk under vacuum and on the surface under reactive gas. However, the preference of M impurities to segregate toward the (111) alloy surface instead of the (100) cannot be directly linked to the strength of M-CO interactions over the alloy surfaces. Except copper, $\mathrm{CO}$ induced segregations occurring on investigated AuM systems are found to be strongly dependent on the surface orientation.

From these results we learn how the acknowledgment of local arrangement of atoms in presence of adsorbed gas is of primary importance before designing specific structure in bimetallic alloys for catalytic purpose.

Acknowledgment: The authors acknowledge the support of EU (COST-MP0903). This work was granted access to the HPC resources of [CCRT/CINES/IDRIS] under the allocation 2012 [x2012086395] made by GENCI (Grand Equipement National de Calcul Intensif]. 


\section{References}

[1] G. A. Somorjai, F. Tao and J. Y. Park, Top. Catal. 47 (2008) 1.

[2] F. Tao, M.E. Grass, Y.W. Zhang, D.R. Butcher, J.R. Renzas, Z. Liu, J.Y. Chung, B.S. Mun, M. Salmeron and G.A. Somorjai, Science 322 (2008) 932.

[3] J.K. Edwards, G.J. Hutchings, Angew. Chem. Int. Ed. 47 (2008) 9192.

[4] J.K. Edwards, B. Solsona, A.F. Carley, A.A. Herzing, C.J. Kiely, G.J. Hutchings, Science 323 (2009) 1037.

[5] M. Chen, D. Kumar, C.W. Yi, D.W. Goodman, Science 310 (2005) 291.

[6] A. Hugon, N. El Kolli, C. Louis, J. Catal. 274 (2010) 239.

[7] A. Lucas-Consuegra, F. Dorado, C. Jiménez-Borja and J. L. Valverde, Appl. Catal. B: Environ. 78 (2008) 222.

[8] A. Lintanf, E. Djurado and P. Vernoux, Solid State Ionics 178 (2008) 1998.

[9] B.O. Chandler, C.G. Long, J.D. Gilberson, C.J. Pursell, G. Vijayaraghavan, K.J.

Stevenson, J. Phys. Chem. C 114 (2010) 11498.

[10] F. Gao, Y. Wang, D.W. Goodman, J. Am. Chem. Soc. 131 (2009) 5734.

[11] S. Zhou, G.S. Jackson, B. Eichhorn, Adv. Funct. Mater. 17 (2007) 3099.

[12] T. Visart de Bocarmé, T.D. Chau, F. Tielens, J. Andrés, P. Gaspard, R.L.C. Wang, H.J. Kreuzer, N. Kruse, J. Chem. Phys. 125 (2006) 054703.

[13] F. Tielens, J. Andrés, T-D. Chau, T. Visart de Bocarmé, N. Kruse, P. Geerlings, Chem. Phys. Lett. 421 (2006) 433.

[14] M. García-Mota and N. López, Phys. Chem. Chem. Phys. 13 (2011) 5790.

[15] S.A. Tenney, W. He, C.C. Roberts, J.S. Ratliff, S.I. Shah, G.S. Shafai, V. Turkowski, T.S. Rahman, and D.A. Chen, J. Phys. Chem. C 115 (2011) 11112.

[16] G. Kresse, J. Hafner, Phys. Rev. B 47 (1993) 58.

[17] G. Kresse, J. Hafner, Phys. Rev. B 49 (1994) 14251.

[18] J.P. Perdew, Y. Wang, Phys. Rev. B 45 (1992) 13244.

[19] P.E. Blochl, Phys. Rev. B 50 (1994) 17953.

[20] Kittel, Introduction to Solid State Physics, seventh edn., Wiley, New York (1996).

[21] H. Guesmi, C. Louis, L. Delannoy, Chem. Phys. Lett. 503 (2011) 97.

[22] A. Dhouib, H. Guesmi, Chem. Phys. Lett. 521 (2012) 98.

[23] B. Zhu, G. Thrimurthu, L. Delannoy, C. Louis, C. Mottet, J. Creuze, B. Legrand and H. Guesmi J. Catal. 308 (2013) 272. 
[24] F.R. de Boer, R. Boom, W.C.M. Mattens, A.R. Miedema, A.K. Niessen, Cohesion in metals, North-Holland, Amsterdam (1988).

[25] G.C. Nelson, Surf. Sci., 59 (1976) 310.

[26] M.J. Kelley, D.G. Swartzfager, V.S. Sundaram, J. Vac. Sci. Technol., 16 (1979) 664.

[27] F. R. Negreiros, E. A. Soares, V. E. de Carvalho and G. Bozzolo, Phys. Rev. B, 76 (2007) 245432.

[28] P. Pyykkö, Chem. Soc. Rev., 37 (2008) 1967

[29] H. C. Potter and J.M. Blakely J. Vac. Sci. Technol., 12 (1975) 6345.

[30] V. Soto-Verdugo, H. Metiu, Surf. Sci., 601 (2007) 5332.

[31] T.V. de Bocarme, M. Moors, N. Kruse, I.S. Atanasov, M. Hou, A. Cerezo, G.D.W. Smith, Ultramicroscopy, 109 (2009) 619.

[32] J. L.C. Fajín, N. D.S. Cordeiro, J. R.B. Gomes, J. Chem. Phys., 138 (2013) 074701.

[33] H. Guesmi, Gold Bulletin, 46 (2013) 213.

[34] B. Hammer, J. Nørskov, Surf. Sci., 343 (1995) 211.

[35] B. Hammer, J. Nørskov, Nature, 376 (1996) 238. 